\title{
QSAR MODELS TO PREDICT EFFECT OF IONIC STRENGTH ON SORPTION OF CHLORINATED BENZENES AND PHENOLS AT SEDIMENT-WATER INTERFACE
}

\author{
BAKUL H. RAO and SHYAM R. ASOLEKAR* \\ Centre for Environmental Science and Engineering, Indian Institute of Technology, \\ Bombay 400 076, India
}

\begin{abstract}
It is hypothesised that the experimental sorption coefficient normalised to the organic carbon fraction of sediment $\left(K_{\mathrm{oc}}^{\exp }\right)$ for non-ionic, hydrophobic, organic pollutant depends upon the molecular properties as well as background ionic strength of the aquatic system. The utility of this concept has been demonstrated by incorporating ionic strength as a parameter in the three quantitative structure activity relationships (QSARs) namely octanol-water partitioning coefficient model (Kow model), the linear solvation energy model (LSE model), and molecular connectivity indices theory (MCI model). Four chlorinated benzenes and two chlorinated phenols were employed in the present study. Sorption experiments using sediment from the Patalganga River were conducted in laboratory (bottle point method) at different ionic strengths (viz. 0.01, 0.05, and $0.10 \mathrm{M}$ ). The $K_{\mathrm{oc}}^{\mathrm{cal}}$ values predicted using Kow model incorporating ionic strength compare reasonably well with the $K_{\mathrm{oc}}^{\exp }$ values $\left(r^{2}=0.60\right.$ and standard error of estimator i.e. SEE=0.35). The LSE model incorporating ionic strength too, was found to be equally good $\left(r^{2}=0.67, \mathrm{SEE}=0.33\right)$. An attempt has also been made to validate the QSARs developed in the present study utilising the sorption parameters experimentally measured by Dewulf et al. (1996) (Water Res. 30, 3130-3138) for sorption of toluene, ethylbenzenes, and xylenes onto the sediments from Belgian Continental Shelf and North Sea, as well as Mader et al. (1997) (Environ. Sci. Technol. 27, 1524-1531) for sorption of di-, tri-, tetra chlorobenzenes on pure mineral oxides namely $\mathrm{Al}_{2} \mathrm{O}_{3}$ and $\mathrm{Fe}_{2} \mathrm{O}_{3}$.
\end{abstract}

Key words - QSARs, structure activity relationship, sorption, hydrophobic organic pollutants, soil-water interface

\section{NOMENCLATURE}

$a, b, c \quad$ multiple regression coefficients

$C_{\mathrm{e}} \quad$ equilibrium concentration of solute in aqueous phase, $\mathrm{mg} / \mathrm{L}$

$C_{0} \quad$ initial concentration of solute in aqueous phase after volatilisation, $\mathrm{mg} / \mathrm{L}$

DLVO double layer valence orbital

$f_{\text {oc }} \quad$ fraction of organic carbon in sediment

IS ionic strength $\left(\frac{1}{2} \Sigma c_{i} z_{i}^{2}\right.$ where $Z_{i}$ and $C_{i}$ are valency and concentration of ion $i$ )

$K_{\mathrm{p}}^{\exp } \quad$ experimental sorption coefficient, $\mathrm{L} / \mathrm{kg}$

$K_{\mathrm{oc}}^{\mathrm{exp}} \quad$ experimental sorption coefficient normalised to organic carbon, $\mathrm{L} / \mathrm{kg}$

$K_{\mathrm{p}}^{\mathrm{cal}} \quad$ QSAR calculated sorption coefficient, $\mathrm{L} / \mathrm{kg}$

$K_{\mathrm{oc}}^{\mathrm{cal}} \quad$ QSAR calculated sorption coefficient and normalised to organic carbon, $\mathrm{L} / \mathrm{kg}$

$K_{\mathrm{oc}}$ sorption coefficient normalised to organic carbon, $\mathrm{L} / \mathrm{kg}$

$K_{\text {ow }} \quad$ octanol-water partition co-efficient

$K_{\text {ow }} \quad$ octanol-water model

LSE linear solvation energy

$M \quad$ mass of sediments, $\mathrm{kg}$

$m_{\chi} \quad$ ' $m$ ' order MCI
MCI molecular connectivity index

MCI0 zero order valence MCI model

MCI0IS zero order valence MCI model with IS

MCI0P zero order valence MCI parabolic model

MCIOPIS zero order valence MCI parabolic model with IS

MCI1 first order valence MCI model

MCI1IS first order valence MCI model with IS

MCI1P first order valence MCI parabolic model

MCI1PIS first order valence MCI parabolic model with IS

MCI2 second order valence MCI model

MCI2IS second order valence MCI model with IS

MCI2P second order valence MCI parabolic model

MCI2PIS second order valence MCI parabolic model with IS

$q_{\mathrm{e}} \quad$ final concentration on soil surface after sorption, $\mathrm{mg} / \mathrm{kg}$

$q_{0} \quad$ inital concentration sorbed on soil surface, $\mathrm{mg} / \mathrm{kg}$

QSAR quantitative structure activity relationship

$r^{2} \quad$ correlation co-efficient

SEE standard error of estimator

$V \quad$ volume of solution, $\mathrm{L}$

$V_{i} / 100$ intrinsic (van der Waals) molecular volume scaled by a factor of 100

Greek symbols

$\alpha \quad$ hydrogen bond acceptor acid

$\beta \quad$ hydrogen bond acceptor base 


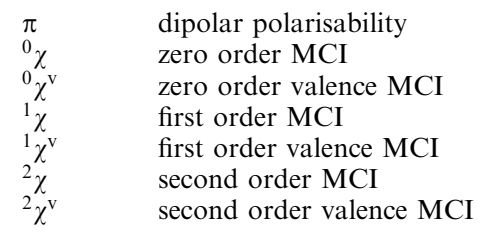

\section{INTRODUCTION}

Many semi-theoretical quantitative structure activity relationships (QSARs) have been proposed to parameterise sorption onto soils/sediments (Baker et al., 1997; Meylan et al., 1992), sorption onto activated carbon (Blum et al., 1994; Luehrs et al., 1996; Belfort et al., 1984), sorption onto wastewater solids (Dobbs et al., 1989), adsorption of organic vapours onto activated carbon (Urano et al., 1982; Nirmalakhandan and Speece, 1993; Prakash et al., 1994), dissolution of compounds (Kamlet et al., 1986; Lane and Loehrs, 1995; Nirmalakhandan and Speece, 1988, 1989; Dunnivent et al., 1992), Henry's law constants (Nirmalakhandan and Speece, 1988; Dunnivent et al., 1992; Nirmalakhandan et al., 1997; Brennan et al., 1998), chemical biotransfer (Dowdy et al., 1996), chemical toxicity (Blum and Speece, 1990; Xu and Nirmalakhandan, 1998); and octanolwater partition coefficients (Sablijic et al., 1993). It is well known that the physico-chemical interactions depend on chemical properties of the pollutant such as aqueous solubilities, octanol/water partition coefficients, or structural characteristics including substituted groups on the pollutant molecule, molar volume of the molecule, topology as well as the intrinsic properties like polarity and polarisability of the pollutant molecules (Westall et al., 1985; Kamlet et al., 1986).

Lately, more attention has been given to applications of QSARs to predict sorption parameters at the soil or sediment interface (Meylan et al., 1992) because such parameterisation can help in a variety of situations including prediction of local and regional impact of aquatic environment, understanding relative importance of fate (Baker et al., 1997) and transport processes in aquatic systems such as oceans, rivers, aquifers, and lakes, remediation of soils, sediments, and aquifers, bioaccumulation, biomagnification, toxicity to life forms, and bioavailability. Some of the most commonly used QSARs for prediction of sorption capacities at the soil-water interface include the octanol-water partitioning coefficient model (Means et al., 1980; Karickhoff, 1981; Piwomi and Banerjee, 1989; Chiou, 1983; Schwarzenbach et al., 1993), the Linear Solvation Energy model (Nirmalakhandan and Speece, 1993; Luehrs et al., 1996), Molecular Connectivity Indices model (Blum et al., 1994; Nirmalakhandan and Speece, 1988; Xu and Nirmalakhandan, 1998); the Solvophobic Theory (Belfort et al., 1984); and the combination of polarisability parameter, molecular connectivity index, and hydrogen bonding index model (Nirmalakhandan et al., 1997). All these QSARs have essentially tried to focus on several complex physico-chemical surface interactions including adsorption, absorption, ion exchange, pore diffusion, redox reaction, precipitation, dissolution, acid/base hydrolysis, formation of co-ordinated complexes giving rise to the polynuclear species (Weber et al., 1991; Banerji et al., 1993; Gao et al., 1998).

In the present study, to simulate the actual estuarine environment of Patalganga River interstitial zone, laboratory sorption studies were carried out using the ionic strength range of $0.01-0.1 \mathrm{M}$ (by adding $\mathrm{NaCl}$ ). Benthic sediments of the riverbed were found to be more or less uniform in size distribution and colour throughout the course of the river. Sediments used in the present study were collected near the source of Patalganga River because natural matrix free of contamination was required for laboratory experiments. Substituted benzenes and phenols (namely benzene, toluene, phenol, chlorobenzene, 1,4-chlorophenol, and 1,4-dichlorobenzene) have been investigated in this research because of their relatively high water-solubility as well as toxicity and they happen to be of great industrial significance as solvents in petroleum, fine chemical, and pesticide industries. Some of these compounds have been used as indicator pollutants for petroleum fraction in the past dealing with sorption behaviour at solid/water interface by many researchers (Breedveld et al., 1997; Nielsen et al., 1996; Abdul et al., 1990; Shahalam et al., 1997). Besides, these solvents are of specific significance in the light of pollution of Patalganga River. Several rural communities abstracting water from the river have accused the chemical industries for disposing treated effluents containing odour-causing solvents including substituted benzenes and phenols.

It is hypothesised that the sorption coefficients normalised to the organic carbon fraction of the sediment $\left(K_{\mathrm{oc}}^{\exp }\right)$ for pollutants depend upon the background ionic strength of the system. This concept has been adopted by incorporating ionic strength term into three QSARs namely octanolwater partitioning coefficient model (Kow model), linear solvation energy model (LSE model), and molecular connectivity indices model (MCI model). It is recognised that these models will help in rapid estimation of sorption capacities while utilising partition coefficients, isotherm equations as well as physico-chemical characteristics of solid/ water interface and pollutants. It is interesting to note that such an approach is appreciated by regulatory authorities as well as government owned and commercial industrial development agencies in India because it can be readily used in environmental impact assessment of disposal of treated industrial effluents and carrying capacity analyses of lakes and rivers so that a meaningful siting and zoning policy for industrialisation and urbanisation could be developed. 
Four chlorinated benzenes and two chlorinated phenols were employed in the present study to investigate their sorptive behaviour at water-sediment interface. Sorption experiments were carried out using the bottle point method at different background ionic strengths $(0.01,0.05$ and $0.1 \mathrm{M})$ at $\mathrm{pH}$ of $6.5 \pm 0.1$. These sorption data were used to develop the three different QSAR models listed above. An attempt has also been made to validate the QSARs developed in the present study utilising the sorption parameters experimentally measured by Dewulf et al. (1996) and Mader et al. (1997).

\section{MATERIALS}

This study is motivated by a real problem involving the Patalganga River which originates near the City of Khopoli (about $80 \mathrm{~km}$ south-east of Mumbai, India) in the ranges of Sahyadri and travels $65 \mathrm{~km}$ in south-west direction to meet the Arabian Sea. Several industrial townships (mostly fine chemicals, pesticides, petrochemical, and pharmaceuticals sector) have been developed all along the stretch of this river. As a result, the conventional drinking water sources (river and dug wells) of dozens of rural communities are irreversibly polluted. The Patalganga River and its catchment is a typical "industrial ecosystem" developed within $100 \mathrm{~km}$ radius of the megacity island of Mumbai and are undergoing rapid transition in the modern post-independence India. Government owned industrial estates and multinational companies along with residential satellite townships have been established in a relatively nonproductive patches of land along the stretch of the river in a setting of traditional agricultural belt. River water in this region is typically rich in natural organic matter and has a vast variation of salinity at the mouth of the creek due to tidal activity in the estuarine region.

Natural uncontaminated sediments from the source of Patalganga River were collected and transported to the laboratory. The river sediments predominantly consists of sandy loam. The sediments were then air dried, sieved through $1 \mathrm{~mm}$ standard sieve, and stored in a cool dry place for later use. Physical properties of the sediment were estimated including organic carbon content, particle size distribution, cation exchange capacity, and surface area, which are believed to affect sorption. The organic carbon of river sediments were found to be $2.43 \% \mathrm{w} / \mathrm{w}$ by the Walley Black method in which potassium dichromate was used to oxidise natural organic carbon in soil and the excess of dichromate is back titrated using ferrous sulphate (Allison, 1965). The BET analysis of the sediment sample showed a surface area of $3.8 \mathrm{~m}^{2} / \mathrm{g}$. The cation exchange capacity of sediment using sodium as index ion was found to be $28.6 \mathrm{meq} / 100 \mathrm{~g}$ (Hesse, 1971). Particle size analysis of dried sediment using dry sieving technique revealed the following size distributions: $1000-500,500-250,250-150,150-75$, $75-37 \mu \mathrm{m}$; and finer than $37 \mu \mathrm{m}$ size fractions weighed 23 , $34,22,16,3$ and $2 \% \mathrm{w} / \mathrm{w}$, respectively.

Substituted benzenes and phenols, namely benzene, toluene, phenol, chlorobenzene, 1,4-chlorophenol, and 1,4dichlorobenzene, used in this study were of pure analytical grade obtained from Aldrich Chemical Co. Ltd., India and were used as received. Stock solutions of the pollutants were prepared in deionised water spiked with analytical grade methanol (one pollutant at a time). These stock solutions in appropriate volumes were injected into aluminium crimped vials containing deionised water $(30 \mathrm{~mL})$ and sediment $(1.00 \mathrm{~g})$ to get the desired initial concentrations of the pollutant of interest. The final concentration of methanol was maintained less than $0.05 \% \mathrm{v} / \mathrm{v}$ so that it did not interfere with the sorption of pollutants. Such experimental methodology is a standard protocol used by many researchers (McGinley et al., 1993; Haderlein et al., 1996; Xia and Ball, 1999). In fact, Haderlein et al. (1996) has reported that methanol or acetonitrile upto $1 \% \mathrm{v} / \mathrm{v}$ did not measurably affect sorption. The maximum aqueous concentration for each of the pollutants was selected to be approximately $50 \%$ of its solubility in water so that all the experiments could be carried out in the linear range of sorption isotherm. The concentrations of pollutants used in the present study have been tabulated in Table 1 .

\section{METHODS}

The sorption isotherm studies, using bottle point method, were conducted using stirred batch reactors (Garbarini and

Table 1. Estimation of experimental partition coefficient $\left(\log K_{\mathrm{p}}^{\mathrm{exp}}\right)$ values for interaction of organic pollutants with Patalganga River sediment using the linear isotherm and the corresponding estimation of organic carbon normalised partition coefficient $\left(\log K_{\mathrm{oc}}^{\mathrm{exp}}\right)^{\mathrm{a}}$

\begin{tabular}{|c|c|c|c|c|c|c|c|c|c|}
\hline \multirow[t]{2}{*}{ Pollutant } & \multirow[t]{2}{*}{$\begin{array}{l}\text { Solubility } \\
(\mathrm{mg} / \mathrm{L})\end{array}$} & \multirow[t]{2}{*}{$\begin{array}{l}\text { Initial conc. in } \\
\text { liquid }(\mathrm{mg} / \mathrm{L})\end{array}$} & \multirow[t]{2}{*}{$\begin{array}{l}\text { Background } \\
\text { IS (M) }\end{array}$} & \multicolumn{2}{|c|}{$\begin{array}{c}\text { Linear isotherm } \\
q_{\mathrm{e}}=K_{\mathrm{p}}^{\exp } C_{\mathrm{e}}\end{array}$} & \multirow{2}{*}{$\begin{array}{l}\log K_{\mathrm{oc}}^{\exp \mathrm{a}} \\
(\mathrm{L} / \mathrm{kg})\end{array}$} & \multirow[t]{2}{*}{$\frac{K_{\mathrm{p}}^{\exp } \text { at } 0.05}{K_{\mathrm{p}}^{\exp } \text { at } 0.01}$} & \multirow[t]{2}{*}{$\frac{K_{\mathrm{p}}^{\exp } \text { at } 0.01}{K_{\mathrm{p}}^{\exp } \text { at } 0.05}$} & \multirow[t]{2}{*}{$\frac{K_{\mathrm{p}}^{\exp } \text { at } 0.1}{K_{\mathrm{p}}^{\exp } \text { at } 0.01}$} \\
\hline & & & & $K_{\mathrm{p}}^{\exp }(\mathrm{L} / \mathrm{kg})$ & $r^{2}$ & & & & \\
\hline Benzene & 820 & $\begin{array}{l}100,200, \\
275,350, \\
450 \\
50,100\end{array}$ & $\begin{array}{l}0.01 \\
0.05 \\
0.1 \\
0.01\end{array}$ & $\begin{array}{l}0.724 \\
0.829 \\
0.912 \\
1.914\end{array}$ & $\begin{array}{l}0.89 \\
0.87 \\
0.99 \\
0.80\end{array}$ & $\begin{array}{l}1.474 \\
1.533 \\
1.574 \\
1.896\end{array}$ & 1.14 & 1.1 & 1.26 \\
\hline Toluene & 515 & $\begin{array}{l}150,200, \\
250\end{array}$ & $\begin{array}{l}0.05 \\
0.1\end{array}$ & $\begin{array}{l}2.369 \\
2.679\end{array}$ & $\begin{array}{l}0.97 \\
0.96\end{array}$ & $\begin{array}{l}1.989 \\
2.042\end{array}$ & 1.24 & 1.13 & 1.39 \\
\hline Phenol & 93,000 & $\begin{array}{l}850,1650, \\
2400, \\
3200,3850 \\
35,70\end{array}$ & $\begin{array}{l}0.01 \\
0.05 \\
0.1 \\
0.01\end{array}$ & $\begin{array}{l}0.0859 \\
0.093 \\
0.095 \\
0.866\end{array}$ & $\begin{array}{l}0.99 \\
0.95 \\
0.94 \\
0.99\end{array}$ & $\begin{array}{l}0.549 \\
0.583 \\
0.592 \\
1.552\end{array}$ & 1.08 & 1.02 & 1.10 \\
\hline Chlorobenzene & 490 & $\begin{array}{l}105,140, \\
175\end{array}$ & $\begin{array}{l}0.05 \\
0.1\end{array}$ & $\begin{array}{l}0.976 \\
1.157\end{array}$ & $\begin{array}{l}0.99 \\
0.99\end{array}$ & $\begin{array}{l}1.604 \\
1.678\end{array}$ & 1.13 & 1.18 & 1.34 \\
\hline 1,4-chlorophenol & 27,000 & $\begin{array}{l}200,350 \\
550,700, \\
875\end{array}$ & $\begin{array}{l}0.01 \\
0.05 \\
0.1\end{array}$ & $\begin{array}{l}0.355 \\
0.531 \\
0.532\end{array}$ & $\begin{array}{l}0.98 \\
0.99 \\
0.94\end{array}$ & $\begin{array}{l}1.165 \\
1.339 \\
1.340\end{array}$ & 1.50 & 1.00 & 1.498 \\
\hline 1,4-dichlorobenzene & 100 & $\begin{array}{l}10,15 \\
20,25, \\
30\end{array}$ & $\begin{array}{l}0.01 \\
0.05 \\
0.1\end{array}$ & $\begin{array}{l}1.036 \\
1.206 \\
1.074\end{array}$ & $\begin{array}{l}0.97 \\
0.86 \\
0.89\end{array}$ & $\begin{array}{l}1.629 \\
1.696 \\
1.645\end{array}$ & 1.16 & 0.89 & 1.04 \\
\hline
\end{tabular}

${ }^{\mathrm{a}} K_{\mathrm{oc}}^{\exp }=K_{\mathrm{p}}^{\exp } / f_{\mathrm{oc}}\left(\right.$ Note $: f_{\mathrm{oc}}=0.0243$ for the Patalganga River sediment. $)$ 
Lion, 1986; Valsaraj, 1989; Valsaraj and Thibodeaux, 1989). For each ionic strength, three replicate sets of glass injection vials were prepared with each containing accurately weighed sediment $(1.00 \mathrm{~g})$ and $30 \mathrm{~mL}$ benzene solution at one of the five predecided initial concentrations (a total of 15 vials). At each ionic strength, two replicate sets of glass injection vials containing only benzene solution at one of the five predecided initial concentrations (blank to estimate volatilisation) were also taken (total 10 vials). All the vials were capped and aluminium foil crimped properly and placed in an end-to-end shaker at $27^{\circ} \mathrm{C}$ and were shaken for a $48 \mathrm{~h}$ period. Preliminary kinetic experiments conducted for each of the six contaminants (using bottle point method) showed that $30-38 \mathrm{~h}$ were sufficient for the system to reach equilibrium. The averages of the pairs of blank readings were then subtracted from the corresponding original initial concentrations to account for volatilisation losses in the headspace.

The samples from the vials were filtered through a $0.45 \mu \mathrm{m}$ glass membrane filter to filter out the sediment particles. The filtrate solution was analysed immediately by gas chromatography (Perkin Elmer) using 15\% SE-30 and $2 \mathrm{~m} \times 2 \mathrm{~mm}$ column using flame ionisation detector and the equilibrium solute concentration was estimated. The above mentioned procedure was repeated to obtain isotherms for other pollutants using five different initial concentrations and three different ionic strengths specified in Table 1 . The $\mathrm{pH}$ of 6.5 was observed upon mixing the soil with water (or pollutant solution). The $\mathrm{pH}$ remained practically invariant owing to the fact that neither any acid/alkali was added during the course of the experiment nor any highly polar pollutant was added to the soil-water mixture. The total amount of solute sorbed in each experiment can be computed from the difference in measured concentrations before and after equilibration, after adjusting for the volume of solution, $V$, and the mass of sediment, $M$. The final concentration on soil surface after sorption, $q_{\mathrm{e}}$, was then computed from the expression

$$
\left(q_{\mathrm{e}}-q_{0}\right)=\left(C_{0}-C_{\mathrm{e}}\right) \frac{V}{M}
$$

where $C_{0}$ is the effective initial concentration of solute in aqueous phase obtained by subtracting volatilisation losses estimated from the corresponding blank experiments from the initial mass added, $C_{\mathrm{e}}$ is the equilibrium concentration in aqueous phase, and $q_{0}$ is the initial amount sorbed onto the soil. In the case of benzene, the extent of volatilisation was found to be $0.37 \%$ in case of $0.01 \mathrm{M}, 0.52 \%$ in case of $0.05 \mathrm{M}$ and $0.57 \%$ in case of $0.1 \mathrm{M}$.

\section{RESULTS AND DISCUSSIONS}

\section{Estimation of experimental sorption coefficients}

The linear isotherm $q_{\mathrm{e}}=K_{\mathrm{p}}^{\exp } C_{\mathrm{e}}$ has been used to interpret batch equilibrium sorption experimental results of hydrophobic compounds onto the sediments/soils by a number of investigators (Breedveld et al., 1997; Valsaraj, 1989; Lee et al., 1989). In this study too, the linear model was used to fit sorption data for all the six pollutants over broad concentration ranges $(0-3850 \mathrm{mg} / \mathrm{L})$ and different background ionic strengths $(0.01,0.5$ and 0.1$)$. The isotherm parameters for particular ionic strengths and pollutants examined in the present study along with the regression co-efficient values, $r^{2}$, are summarised in Table 1 . The $K_{\mathrm{p}}^{\exp }$ values (i.e. $q_{\mathrm{e}} / C_{\mathrm{e}}$ ) are converted to $K_{\mathrm{oc}}^{\exp }$ values by normalising the $K_{\mathrm{p}}^{\exp }$ to the organic carbon fraction of the sediment $\left(f_{\mathrm{oc}}\right)$ using the following equation $K_{\mathrm{oc}}^{\exp }=K_{\mathrm{p}}^{\exp } / f_{\mathrm{oc}} \quad$ (Karickhoff et al., 1979; Garbarini and Lion, 1986) (given in Table 1).

The $\log K_{\mathrm{p}}^{\exp }$ values, calculated experimentally and given in Table 1, provide an indication of sorption capacity. Among the pollutants, the $\log K_{\mathrm{p}}^{\exp }$ values increased with an increase in hydrophobicity of the pollutant molecule. The more hydrophobic the pollutant, the more is the sorption that occurs onto the sediment.

Sorption capacity for any organic pollutant is believed to depend upon three main factors namely (a) the sorbate characteristics like polarity, hydrophobicity, molecular size, aqueous solubility, functional groups present and branching, (b) the solution of the system like $\mathrm{pH}$, temperature, ionic strength and (c) the sorbent characteristics like surface area, organic matter, mineral surfaces, pore size, etc., (Belfort, 1979). In the present study, when comparison of solubility of the pollutants studied with $K_{\mathrm{p}}$ values was done (Table 1), it was observed that decrease in solubility brought about an increase in $K_{\mathrm{p}}$ values.

Al-Bahrani and Martin (1976) have studied the sorption capacities of homologues of organic compounds with comparable solubilities onto activated carbon. Even for compounds with comparable solubility, when sequenced in decreasing values of solubilities; the compounds happen to have a clear increasing value of $K_{\mathrm{p}}$ in the same sequence. For example, $o$-cresol reportedly had sorption capacity of $2.22 \times 10^{-3} \mathrm{~g} \mathrm{~mol} / \mathrm{g}$ and a solubility of $2.5 \%$ when compared with $o$-chlorophenol having sorption capacity of $2.12 \times 10^{-3} \mathrm{~g} \mathrm{~mol} / \mathrm{g}$ and a solubility of $2.8 \%$. Further, in the present study, in case of benzene, toluene, chlorobenzene and phenol, for a given pollutant molecule, the increasing background IS gave rise to decreasing solubility. As seen from Table 1, the analogous sequencing of decreasing solubility was observed to be associated with increasing $K_{\mathrm{p}}$ for each one of the above molecules.

In case of 1,4-chlorophenol, the $K_{\mathrm{p}}$ values at 0.05 and $0.1 \mathrm{M}$ background ionic strength are comparable $(0.531$ and $0.532 \mathrm{~L} / \mathrm{kg})$, but the value at $0.01 \mathrm{IS}$ is much smaller $(0.355 \mathrm{~L} / \mathrm{kg})$. However, there is a clear trend of increase in $K_{\mathrm{p}}$ value with an increase in IS which can be explained on the basis of decrease in solubility of 1,4-chlorophenol associated with the increase in IS. The abrupt increase of $K_{\mathrm{p}}$ (from 0.355 to $0.531 \mathrm{~L} / \mathrm{kg}$ ), while changing the IS from 0.01 to 0.05 is difficult to explain.

In case of 1,4-dichlorobenzene, the $K_{\mathrm{p}}$ values corresponding to three ISs seem to increase and then decrease when IS is increased from 0.01 to 0.05 to 0.1 , respectively. It is interesting to note that 1,4dichlorobenzene has the least solubility $(50 \mathrm{mg} / \mathrm{L})$ amongst the pollutants studied. Owing to the fact that 1,4-dichlorobenzene has rather low solubility, it is highly inexplicable that a $20 \%$ jump in $K_{\mathrm{p}}$ value (1.036-1.206) occurs when the background IS is 
changed from 0.01 to $0.05 \mathrm{M}$. However, the jump in $K_{\mathrm{p}}(1.036-1.074)$ for a change in IS from 0.01 to 0.1 appears to be reasonable considering the low solubility of 1,4-dichlorobenzene. Clearly, the $K_{\mathrm{p}}$ value of 1.206 at 0.05 IS could have been a result of experimental/analytical error.

The plausible explanation for the observed increase in sorption at the higher background ionic strength could be that when ionic strength increases, the cations get associated with the anionic groups on the humic acid (both, dissolved in water and sorbed onto the soils). Though the anionic group of humic acid, $\mathrm{HA}$ is available $\left(\mathrm{HA} \rightarrow \mathrm{H}^{+}+\mathrm{A}^{-}\right)$ only at alkaline medium, even at near neutral conditions there will be sizable negative sites available on the humic material. Therefore, it is conjectured that the negative sites on the humic material will be satisfied by the cations added and thus help in bridging interactions between the different parts of the humic chain. These interactions may bring about flocculation of free colloidal humic matter as well as curl the sorbed humic material closer to each other. Another reason for flocculation of humic matter could probably be the reduction in the double layer thickness according to the DLVO theory (Keiding and Nielsen, 1997). However, the present study does not address the increment of negative sites neutralised by $\mathrm{Na}^{+}$and the relationship of this process with background ionic strength as well as $\mathrm{pH}$.

Due to the flocculation of free colloidal humic matter, the weight and sizes of flocs increase leading to settling of flocs and thereby, the associated sorbed pollutants are transferred from aquatic phase to the colloidal phase bringing about a decrease in solution concentration of the contaminant. The sorbed humic matter, due to curling, form hydrophobic pseudomicelles, thereby providing a favourable environment for pollutants (Engebretson and Wandruszka, 1998; Romkens and Dolfing, 1998). Also, curling of natural organic matter could bring about an exposure of the mineral surfaces to the pollutant, thereby leading to an increase in sorption onto mineral surfaces. This too could lead to a decrease in solution concentration of the pollutants. Thus, ionic strength enhances the uptake of pollutants by partitioning it into the natural organic carbon as well as onto mineral surfaces (Luthy et al., 1997).

The second plausible explanation could be that when a salt is dissolved in water it ionises and the ions bind water into hydration shell thereby reducing the volume of aqueous solution. For any non-polar compound, this tightly bound water is unavailable to dissolve into thus leading to a decrease in solubility. The sorption capacity $\left(K_{\mathrm{p}}^{\exp }\right)$ in the presence of higher IS was more than the sorption capacity at low ionic strength. It can be noted here that, during our experiments, volatilisation was also higher at higher ionic strength. For example in case of benzene, the extent of volatilisation was found to be $0.37 \%$ in case of $0.01 \mathrm{M}, 0.52 \%$ in case of $0.05 \mathrm{M}$ and $0.57 \%$ in case of $0.1 \mathrm{M}$.

According to Karickhoff (1984), the predominant "salt effect" for neutral pollutants is derived from the aqueous-phase activity coefficient using the Setschenow equation. An increase in the hydrophobic sorption was observed with an increase in the background salt concentration for the salts with positive Setschenow constant. For example, Setschenow constant for $\mathrm{NaCl}$ is $0.16 \mathrm{~L} / \mathrm{mol}$, and it has been reported that the sorption coefficient $\left(K_{\mathrm{p}}^{\exp }\right)$ increases by a factor of $10^{0.08}$ (i.e. approximately 1.2 times) with every $0.5 \mathrm{M}$ increase in $\mathrm{NaCl}$ concentration. In the present study also, for a given pollutant (Table 1), there is an increase in $\log K_{\mathrm{p}}^{\exp }$ value with an increase in ionic strength (brought about by using $\mathrm{NaCl}$ ). However, in this study, it was found that there was no fixed proportionality between the $\log K_{\mathrm{p}}^{\exp }$ values at different ionic strengths.

Murphy et al. (1994) studied the influence of ionic strength, $\mathrm{pH}$ and cation valence on to the structure of mineral bound humic material. They found that increase in ionic strength brings out curling of humic material due to reduction in electrostatic repulsion between adjacent functional groups. Further, they also found that the hematite mineral surface promoted a more open and elongated structure of humic material which was favourable for sorption of hydrophobic organic compounds. Similar observation has been reported by Schwarzenbach et al. (1993) and Luthy et al. (1997). The observed nonproportional increase in $\log K_{\mathrm{p}}^{\exp }$ values can be attributed to such factors like changes in coiled structure of natural organic matter and increase in the available mineral surface.

Relative impact of variation of ionic strength on the $K_{\mathrm{p}}^{\exp }$ ratios for a given pollutant molecule is essentially governed by ionisability of molecule. Among the molecules investigated in the present study, phenol and 1,4-chlorophenol are ionisable whereas among non-ionisable chlorobenzene and 1,4dichlorobenzene are polarisable, and benzene and toluene are non-polarisable. In order to evaluate the impact of ionic strength variation on the $K_{\mathrm{p}}^{\exp }$ values of the above molecules, the $K_{\mathrm{p}}^{\exp }$ ratio at different IS were calculated and are summarised in Table 1. Clearly, the ratios for ionisable molecules least suggest that the variation of IS did not cause significant alteration in $K_{\mathrm{p}}^{\exp }$. Further, the $K_{\mathrm{p}}^{\exp }$ ratios at different ionic strengths increases in the following sequence: ionisable $<$ polarizable $<$ nonpolar.

As stated earlier, solubility of compound decreases with increased ionic strength. By comparing the $K_{\mathrm{p}}^{\exp }$ ratios at different ISs (reported in Table 1), it can be concluded that the effect of reduction in solubility with increase in ionic strength is the most pronounced in case of non-polar compounds (giving rise to higher $K_{\mathrm{p}}^{\exp }$ ratios). Thus, the effect of ionic strength is less significant for ionisable molecules like 
phenol as compared to that of either polarisable molecules like chlorobenzene or non-polar molecules like benzene.

It must be noted here that, as stated earlier, the high $K_{\mathrm{p}}^{\text {exp }}$ values in case of 1,4-chlorophenol and 1,4dichlorobenzene at 0.05 IS were difficult to explain and hence the ratios involving $K_{\mathrm{p}}^{\exp }$ at 0.05 IS (reported in italics type-face in Table 1) have been ignored, while arriving at the inference regarding impact of IS on $K_{\mathrm{p}}^{\exp }$ values.

\section{Estimation of sorption coefficients using QSARS}

Many semi-theoretical models describing the QSARs have been proposed to predict the sorption parameters including the octanol-water partitioning coefficient, the LSE model, (Nirmalakhandan and Speece, 1993; Luehrs et al., 1996), the MCI model (Blum et al., 1994; Nirmalakhandan and Speece, 1988), and the solvophobic theory (Belfort et al., 1984). While utilising the above QSARs, it is hypothesised that the sorption coefficients normalised to the organic carbon fraction of the sediment $\left(K_{\mathrm{oc}}^{\exp }\right)$ values for pollutants in fact depend upon the background ionic strength of the system and the validity of this approach has been demonstrated by incorporating the ionic strength term into the three QSARs namely octanol-water partitioning coefficient model (Kow model), the LSE model, and the MCI model.

Kow model. The octanol water coefficients for the six pollutants studied (listed in Table 2) were obtained from Schwarzenbach et al. (1993) and were correlated with the experimentally obtained $\log K_{\mathrm{oc}}^{\exp }$ values. A linear regression of $\log K_{\mathrm{oc}}^{\exp }$ as a function of $\log K_{\text {ow }}$ for the system studied yielded the following equation, and a correlation coefficient $\left(r^{2}\right)$ of 0.57
$(N=18)$ was obtained:

$$
\log K_{\mathrm{oc}}^{\exp }=0.064+0.541 \log K_{\mathrm{ow}}
$$

There is a linear relation between the $\log K_{\mathrm{oc}}^{\exp }$ and $\log K_{\text {ow }}$ which confirms the dependence of sorption on organic matter. Similar observation was made by Dewulf et al. (1996). But as can be seen, the slope of linear equation between the $\log K_{\mathrm{oc}}^{\mathrm{exp}}$ and $\log K_{\mathrm{ow}}$ is less than $1(0.541)$ i.e., there is no proportional increase in $\log K_{\mathrm{oc}}^{\mathrm{exp}}$ with an increase in $\log K_{\mathrm{ow}}$ which could be attributed to lower lipophilicity of the organic carbon as compared to octanol. A multiple regression incorporating the ionic strength term into the Kow model yields the following equation and a correlation coefficient $\left(r^{2}\right)$ of $0.57(N=18)$ :

$$
\log K_{\mathrm{oc}}^{\exp }=0.006+0.541 \log K_{\mathrm{ow}}+1.09 \text { IS }
$$

LSE model. In the LSE model, the whole array of solvatochromic parameters $\left(V_{\mathrm{i}} / 100, \pi, \alpha\right.$, and $\left.\beta\right)$ were obtained from Luehrs et al. (1996) for all the pollutants used in this study excepting 1,4chlorophenol which was calculated by the procedure given by Hickey and Passino-Reader (1991). The solvatochromic parameters for the various pollutants studied are as given in Table 2 . It can be seen from Tables 1 and 2 that as the intrinsic molar volume $\left(V_{\mathrm{i}} / 100\right)$ increases the sorption also increases (i.e., the $\log K_{\mathrm{oc}}^{\exp }$ values increases) for benzene, toluene, chlorobenzene, and 1,4-dichlorobenzene. The exceptions such as phenol and 1,4-chlorophenol shown in the above trend may be attributed to the increase in hydrogen bond acceptor base $(\beta)$ which leads to a decrease in sorption.

It can be seen that the $\alpha$ term is not significant and hence has been omitted. Carrying out a multiple

\begin{tabular}{|c|c|c|c|c|c|c|c|c|}
\hline \multirow[t]{2}{*}{ Pollutant } & \multirow[t]{2}{*}{$\log K_{\text {ow }}{ }^{\mathrm{a}}$} & \multicolumn{4}{|c|}{ LSE parameter $^{\mathrm{b}}$} & \multicolumn{3}{|c|}{ MCI parameters ${ }^{\mathrm{c}}$} \\
\hline & & $\begin{array}{l}\text { Dipolar } \\
\text { polarisability, } \pi\end{array}$ & $\begin{array}{l}\text { Intrinsic } \\
\text { molecular } \\
\text { volume, } V_{i} / 100\end{array}$ & $\begin{array}{l}\text { Hydrogen bond } \\
\text { acceptor base, } \beta\end{array}$ & $\begin{array}{l}\text { Hydrogen bond } \\
\text { acceptor acid, } \alpha\end{array}$ & $0 \chi \mathrm{v}$ & $1 \chi \mathrm{v}$ & $2 \chi \mathrm{v}$ \\
\hline Benzene & 2.13 & 0.59 & 0.491 & 0.14 & 0.00 & 3.464 & 2.00 & 1.1547 \\
\hline Toluene & 2.69 & 0.55 & 0.592 & 0.11 & 0.00 & 4.3865 & 2.4104 & 1.65 \\
\hline Phenol & 1.45 & 0.72 & 0.536 & 0.33 & 0.60 & 3.834 & 2.1343 & 1.3355 \\
\hline Chlorobenzene & 2.92 & 0.71 & 0.581 & 0.07 & 0.00 & 4.582 & 2.5083 & 1.7674 \\
\hline 1,4-chlorophenol & 2.67 & $0.84^{\mathrm{d}}$ & $0.626^{\mathrm{d}}$ & $0.29^{\mathrm{d}}$ & $0.60^{\mathrm{d}}$ & 4.9518 & 2.6425 & 1.944 \\
\hline 1,4-Dichlorobenzene & 3.38 & 0.7 & 0.67 & 0.03 & 0.00 & 5.699 & 3.0166 & 2.3801 \\
\hline$o$-Xylene & 3.12 & $0.51^{\mathrm{d}}$ & $0.687^{\mathrm{d}}$ & $0.16^{\mathrm{d}}$ & $0.00^{\mathrm{d}}$ & $5.3094^{\mathrm{e}}$ & $2.8273^{\mathrm{e}}$ & $2.0843^{\mathrm{e}}$ \\
\hline$m$-Xylene & 3.2 & $0.51^{\mathrm{d}}$ & $0.687^{\mathrm{d}}$ & $0.16^{\mathrm{d}}$ & $0.00^{\mathrm{d}}$ & $5.3094^{\mathrm{e}}$ & $2.8214^{\mathrm{e}}$ & $2.1582^{\mathrm{e}}$ \\
\hline$p$-Xylene & 3.18 & 0.51 & 0.671 & 0.12 & 0.00 & $5.3094^{\mathrm{e}}$ & $2.8214^{\mathrm{e}}$ & $2.1547^{\mathrm{e}}$ \\
\hline Ethylbenzene & 3.15 & 0.53 & 0.687 & 0.12 & 0.00 & $5.0939^{\mathrm{e}}$ & $2.9713^{\mathrm{e}}$ & $1.8392^{\mathrm{e}}$ \\
\hline 1,2,4-trichlorobenzene & $3.97^{\mathrm{f}}$ & $0.75^{\mathrm{f}}$ & $0.761^{\mathrm{f}}$ & $0.00^{\mathrm{f}}$ & $0.00^{\mathrm{f}}$ & 6.8177 & 3.5308 & 2.9103 \\
\hline 1,2,3,4-tetrachlorobenzene & $4.64^{\mathrm{f}}$ & $0.7^{\mathrm{f}}$ & $0.851^{\mathrm{f}}$ & $0.00^{\mathrm{f}}$ & $0.00^{\mathrm{f}}$ & 7.9356 & 4.051 & 3.3546 \\
\hline
\end{tabular}

Table 2. Thermodynamic parameters needed for the QSAR models for the experimental and validation pollutant molecules

${ }^{a}$ Values obtained from Schwarzenbach et al. (1993).

${ }^{b}$ Values obtained from Luehrs (1996).

${ }^{\mathrm{c}}$ Values calculated as per the method given by Kier and Hall (1976).

${ }^{\mathrm{d}}$ Values calculated as per the method given by Hickey and Passino-Reader (1991).

${ }^{\mathrm{e}}$ Values obtained from Kier and Hall (1976).

${ }^{\mathrm{f}}$ Values obtained from Baker et al. (1997) data base. 
regression of $\log K_{\mathrm{oc}}^{\mathrm{exp}}$ as a function of intrinsic molar volume $\left(V_{\mathrm{i}} / 100\right)$, dipolar-polarisability $(\pi)$ and hydrogen bond acceptor base $(\beta)$ for the system studied yielded the following equation and a correlation coefficient $\left(r^{2}\right)$ of $0.74(N=18)$ :

$$
\log K_{\mathrm{oc}}^{\exp }=1.615+2.419 \frac{V_{i}}{100}-1.821 \pi-2.102 \beta
$$

The ionic strength parameter was incorporated to improve the overall quality of the model by carrying out a multiple regression of $\log K_{\mathrm{oc}}^{\exp }$ as a function of intrinsic molar volume $\left(V_{\mathrm{i}} / 100\right)$, dipolar-polarisability $(\pi)$ and hydrogen bond acceptor base $(\beta)$ and the various ionic strengths used for the system studied which yielded the following equation and a correlation coefficient $\left(r^{2}\right)$ of 0.75 $(N=18)$ :

$$
\begin{aligned}
\log K_{\mathrm{oc}}^{\exp }= & 1.557+2.419 \frac{V_{i}}{100}-1.821 \pi-2.102 \beta \\
& +1.095 \mathrm{IS}
\end{aligned}
$$

MCI model. Kier and Hall (1976) have proposed a parabolic relation between experimental partition coefficient and the molecular connectivity index $\left({ }^{m} \chi\right)$ instead of using different indices in a multiple regression. Their general equation for the relationship can be represented as follows:

$$
\log \text { activity }=a\left({ }^{m} \chi^{\mathrm{v}}\right)+b\left({ }^{m} \chi^{\mathrm{v}}\right)^{2}+c .
$$

The zero, first, and second order valence molecular connectivity indices $\left({ }^{0} \chi^{\mathrm{v}},{ }^{1} \chi^{\mathrm{v}}\right.$ and $\left.{ }^{2} \chi^{\mathrm{v}}\right)$ for the pollutants were calculated using the method described by Kier and Hall (1976) and are shown in Table 2. In this study, too, a similar approach of parabolic relation between experimental partition coefficient and the molecular connectivity index $\left({ }^{m} \chi\right)$ was employed and the following MCI modelequations along with the corresponding $r^{2}$ and $N$ values were obtained.

MCIOPIS model (zero order valence MCI parabolic relation with $\mathrm{IS})$ :

$$
\begin{gathered}
\log K_{\mathrm{oc}}^{\exp }=-0.526-0.655^{0} \chi^{\mathrm{v}}-0.05\left({ }^{0} \chi^{\mathrm{v}}\right)^{2} \\
+1.095 \text { IS } \\
\left(r^{2}=0.12\right) \quad(N=18)
\end{gathered}
$$

MCIIIS model (first order valence MCI linear relation with IS):

$$
\begin{aligned}
& \log K_{\mathrm{oc}}^{\exp }=0.218+0.474^{1} \chi^{\mathrm{v}}+1.095 \mathrm{IS} \quad\left(r^{2}=0.14\right) \\
& (N=18)
\end{aligned}
$$

MCI1P model (first order valence MCI parabolic relation without IS):

$$
\begin{aligned}
& \log K_{\mathrm{oc}}^{\exp }=-2.396+2.651^{1} \chi^{\mathrm{v}}-0.436\left({ }^{1} \chi^{\mathrm{v}}\right)^{2} \\
& \left(r^{2}=0.14\right) \quad(N=18)
\end{aligned}
$$

MCIIPIS model (first order valence MCI parabolic relation with IS):

$$
\begin{gathered}
\log K_{\mathrm{oc}}^{\exp }=-2.454+2.651^{1} \chi^{\mathrm{v}}-0.436\left({ }^{1} \chi^{\mathrm{v}}\right)^{2} \\
+1.095 \text { IS } \\
\left(r^{2}=0.15\right) \quad(N=18)
\end{gathered}
$$

MCI2PIS model (second order valence MCI parabolic relation with IS):

$$
\begin{gathered}
\log K_{\mathrm{oc}}^{\exp }=0.045+1.207^{2} \chi^{\mathrm{v}}-0.236\left({ }^{2} \chi^{\mathrm{v}}\right)^{2}+1.095 \mathrm{IS} \\
\left(r^{2}=0.13\right) \quad(N=18)
\end{gathered}
$$

It can be noted that $r^{2}$ values obtained in the above regression exercises are more or less equal and are indicative of poor correlation. It was found that the first-order valence MCI with IS, both linear and parabolic relations (MCI1IS and MCI1PIS models) fitted marginally better than the other MCI models. Similar conclusion has been reported by Kier and Hall (1976), who have stated that while establishing a parabolic relation between partition coefficient and ${ }^{m} \chi^{\mathrm{v}}$, the order of $\chi$ (i.e., $m$ ) in all probability would be 1. Among the two, first order valence MCI linear relation with IS (MCI1IS), and first order valence MCI parabolic relation with IS (MCI1PIS), introduction of the parabolic term into the MCI1PIS model improved the $r^{2}$ value only marginally.

\section{Comparison of developed QSARS}

Once the various QSARs, namely Kow, LSE, MCI0PIS, MCI1IS, MCI1PIS and MCI2PIS models incorporating ionic strength were developed, sorption coefficient normalised to organic carbon $\left(\log K_{\mathrm{oc}}^{\mathrm{cal}}\right)$ for the substituted benzenes and phenols were predicted using the above-mentioned QSARs. Two statistical tests were used to assess the "goodness of fit", namely, the correlation coefficient $\left(r^{2}\right)$ which represents the fraction of overall variance in experimental $\log K_{\mathrm{oc}}$ when compared with model predicted values and the standard error of estimator (SEE) which represents the average residual error between the experimentally measured $\log K_{\mathrm{oc}}$ and the model calculated $\log K_{\mathrm{oc}}$ normalised to the number of observation in the data set. SEE was calculated as

$$
\mathrm{SEE}=\sqrt{\frac{\sum_{i=1}^{N}\left(\log K_{\mathrm{oc}}^{\mathrm{exp}}-\log K_{\mathrm{oc}}^{\mathrm{cal}}\right)_{\mathrm{i}}^{2}}{N-2}}
$$

where $N$ is the total number of pollutants at different IS's used in the experiment. The values for $r^{2}$ and SEE corresponding to the six pollutant molecules experimentally studied in the present study and eight QSARs developed here have been tabulated in Table 3.

The correlation between calculated and experimental $\log K_{\mathrm{oc}}$ for the Kow model was found to have $r^{2}$ value of 0.53 and SEE of 0.367 (Table 3). The correlation between calculated and experimental log $K_{\text {oc }}$ increased from 0.53 for the Kow model to 0.60 for Kow model with IS (Table 3). Table 3 also shows 
the SEE values for the Kow without IS model as 0.37, while the SEE values for the Kow with IS is 0.35 . Further, the correlation coefficient $\left(r^{2}\right)$ for the calculated and experimental $\log K_{\mathrm{Oc}}^{\exp }$ for the LSE model without and with IS is 0.60 and 0.67 , respectively (Table 3 ). Table 3 also shows the SEE values for the LSE model without and with Ionic Strength as 0.35 and 0.33 , respectively. It was found that, in MCI, Kow and LSE models, incorporation of IS term into the models improved the correlation coefficients (for MCI1 model $r^{2}=0.12$, while for MCI1IS model $r^{2}=0.14$ ).

The parity plot for comparison between $\log K_{\mathrm{oc}}^{\mathrm{cal}}$ using the Kow model incorporating IS and the LSE model without and with IS QSARs developed in this study with the experimental $\log K_{\mathrm{oc}}^{\mathrm{exp}}$ measured in this study shows an $r^{2}$ value of 0.69 and SEE of 0.25 (Fig. 1). Among the various models developed in the present study, the Kow model incorporating IS $\left(r^{2}=0.60, \mathrm{SEE}=0.35\right)$ and the LSE model without and with IS $\left(r^{2}=0.60\right.$ and $0.67, \mathrm{SEE}=0.35$ and 0.33 , respectively), were found to be relatively superior.

\section{Validation of the developed models}

An attempt has been made here to validate the QSARs developed in the present study utilising the sorption parameters experimentally measured by Dewulf et al. (1996) for sorption of toluene, ethylbenzenes, and xylenes onto the sediments from Belgian Continental Shelf, and North Sea, as well as Mader et al. (1997) for sorption of di-, tri- and tetra chlorobenzenes on pure mineral oxides namely $\mathrm{Al}_{2} \mathrm{O}_{3}$ and $\mathrm{Fe}_{2} \mathrm{O}_{3}$. The validation data were selected in such a manner that wide variations in IS were dealt with. For example, Mader et al. (1997) have used low ISs $(I=0.0059 \mathrm{M})$ while, Dewulf et al. (1996) have used high ionic strength $(I=0.678)$, while in the present study three different ISs $(I=0.01,0.05$ and 0.1$)$ were used. The data set from two researchers namely Dewulf et al. (1996) and Mader et al. (1997) were used to predict $\log K_{\mathrm{oc}}$ values for the substituted benzenes using the Kow, LSE, MCI0PIS, MCI1IS, MCI1PIS, and MCI2PIS QSAR models incorporating ionic strength developed in this study. The IS incorporated QSAR models were only used as both the researchers namely Dewulf et al. (1996) and Mader et al. (1997) have background ionic strength in them.

The octanol water coefficients for toluene, ethylbenzene, xylenes, and 1,4-dichlorobenzene were obtained from Schwarzenbach et al. (1993), while the octanol water coefficients for tri and tetra chlorobenzenes were obtained from Baker et al. (1997). For the LSE model, the whole array of solvatochromic parameter $\left(V_{\mathrm{i}} / 100, \pi, \alpha\right.$, and $\left.\beta\right)$ for toluene, $p$-xylene, and ethylbenzene were obtained from Luehrs et al. (1996), parameters for tri and tetra chlorobenzenes were obtained from Baker et al. (1997), while parameters for $o$-xylene and $m$-xylene were calculated by the procedure given by Hickey and Passino-Reader (1991). The topological descriptor parameters (i.e., $\left.{ }^{0} \chi^{\mathrm{v}},{ }^{1} \chi^{\mathrm{v}},{ }^{2} \chi^{\mathrm{v}}\right)$ of $o-, m$-, and $p$-xylenes and ethylbenzene have been obtained from Kier and Hall (1976) and for toluene and di-, tri- and tetra-chlorobenzene were calculated as per the

Table 3. Model predicted $\log K_{\mathrm{oc}}^{\mathrm{calc}}$ values and corresponding experimental $\log K_{\mathrm{oc}}^{\mathrm{exp}}$ values for the pollutants investigated in the present study along with the statistical tests estimating the goodness of fit

\begin{tabular}{|c|c|c|c|c|c|c|c|c|c|}
\hline \multirow[t]{2}{*}{ Pollutant } & \multirow[b]{2}{*}{$\log K_{\mathrm{oc}}^{\exp }$} & \multicolumn{8}{|c|}{ Calculated $\log K_{\mathrm{oc}}$ values using a given QSAR model } \\
\hline & & Kow model & $\begin{array}{l}\text { Kow } \\
\text { model } \\
\text { with IS }\end{array}$ & $\begin{array}{l}\text { LSE } \\
\text { model }\end{array}$ & $\begin{array}{l}\text { LSE } \\
\text { model } \\
\text { with IS }\end{array}$ & $\begin{array}{l}\text { MCI0PIS } \\
\text { model } \\
\text { with IS }\end{array}$ & $\begin{array}{l}\text { MCI1IS } \\
\text { model } \\
\text { with IS }\end{array}$ & $\begin{array}{l}\text { MCI1PIS } \\
\text { model } \\
\text { with IS }\end{array}$ & $\begin{array}{l}\text { MCI2PIS } \\
\text { model } \\
\text { with IS }\end{array}$ \\
\hline \multirow[t]{3}{*}{ Benzene } & 1.474 & 1.216 & 1.169 & 1.435 & 1.387 & 1.145 & 1.176 & 1.117 & 1.135 \\
\hline & 1.533 & 1.216 & 1.213 & 1.435 & 1.431 & 1.189 & 1.220 & 1.161 & 1.179 \\
\hline & 1.574 & 1.216 & 1.267 & 1.435 & 1.486 & 1.244 & 1.275 & 1.216 & 1.233 \\
\hline \multirow[t]{3}{*}{ Toluene } & 1.896 & 1.519 & 1.472 & 1.815 & 1.767 & 1.387 & 1.371 & 1.417 & 1.405 \\
\hline & 1.989 & 1.519 & 1.515 & 1.815 & 1.811 & 1.431 & 1.414 & 1.461 & 1.449 \\
\hline & 2.042 & 1.519 & 1.570 & 1.815 & 1.866 & 1.486 & 1.469 & 1.515 & 1.504 \\
\hline \multirow[t]{3}{*}{ Phenol } & 0.549 & 0.848 & 0.801 & 0.907 & 0.860 & 1.252 & 1.240 & 1.231 & 1.247 \\
\hline & 0.583 & 0.848 & 0.845 & 0.907 & 0.904 & 1.296 & 1.284 & 1.275 & 1.291 \\
\hline & 0.592 & 0.848 & 0.899 & 0.907 & 0.959 & 1.351 & 1.338 & 1.330 & 1.345 \\
\hline \multirow[t]{3}{*}{ Chlorobenzene } & 1.552 & 1.643 & 1.596 & 1.581 & 1.534 & 1.428 & 1.417 & 1.467 & 1.452 \\
\hline & 1.604 & 1.643 & 1.640 & 1.581 & 1.577 & 1.472 & 1.461 & 1.510 & 1.496 \\
\hline & 1.678 & 1.643 & 1.695 & 1.581 & 1.632 & 1.527 & 1.516 & 1.565 & 1.551 \\
\hline \multirow[t]{3}{*}{ 1,4-Chlorophenol } & 1.165 & 1.508 & 1.461 & 0.991 & 0.943 & 1.494 & 1.481 & 1.521 & 1.511 \\
\hline & 1.339 & 1.508 & 1.505 & 0.991 & 0.987 & 1.538 & 1.524 & 1.565 & 1.554 \\
\hline & 1.340 & 1.508 & 1.559 & 0.991 & 1.042 & 1.593 & 1.579 & 1.620 & 1.609 \\
\hline \multirow[t]{3}{*}{ 1,4-Dichlorobenzene } & 1.629 & 1.892 & 1.845 & 1.899 & 1.851 & 1.586 & 1.658 & 1.591 & 1.592 \\
\hline & 1.696 & 1.892 & 1.889 & 1.899 & 1.895 & 1.630 & 1.702 & 1.635 & 1.636 \\
\hline & 1.645 & 1.892 & 1.943 & 1.899 & 1.950 & 1.684 & 1.756 & 1.690 & 1.691 \\
\hline $\mathrm{SEE}^{\mathrm{a}}$ & & 0.367 & 0.347 & 0.352 & 0.331 & 0.434 & 0.412 & 0.431 & 0.431 \\
\hline$r^{2}$ & & 0.531 & 0.602 & 0.602 & 0.668 & 0.290 & 0.395 & 0.264 & 0.063 \\
\hline
\end{tabular}

${ }^{\mathrm{a}} \mathrm{SEE}=\sqrt{\frac{\sum_{i=1}^{N}\left(\log K_{\mathrm{oc}}^{\mathrm{exp}}-\log K_{\mathrm{oc}}^{\mathrm{cal}}\right)_{\mathrm{i}}^{2}}{N-2}}$. 


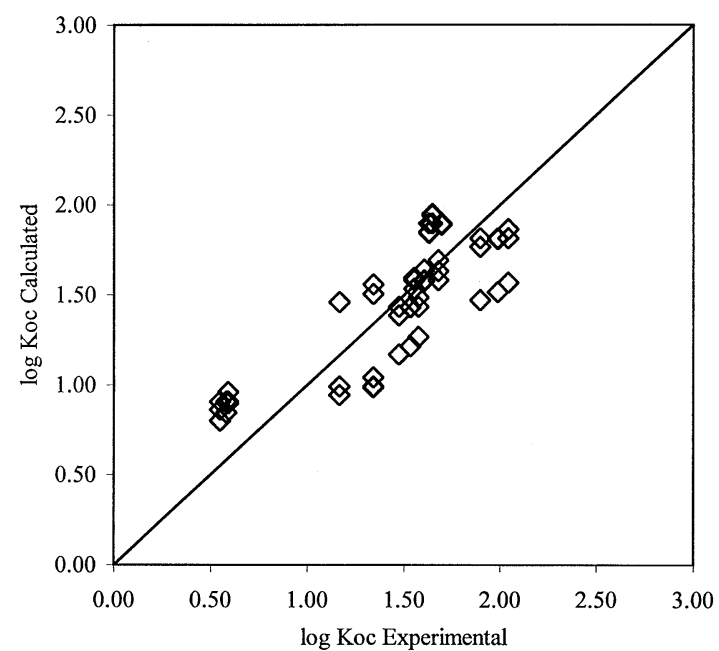

Fig. 1. Parity plot for comparison between $\log K_{\mathrm{oc}}$ calcu lated using developed QSARs $\left(K_{\text {ow }}\right.$, LSE with and without

IS) with $\log K_{\mathrm{oc}}$ experimental measured in laboratory.

method mentioned in Kier and Hall (1976) and utilised in the MCI models developed in this study. All the above-mentioned parameters needed for validation of QSARs have also been listed in Table 2. Sorption coefficient normalised to organic carbon $\left(\log K_{\mathrm{oc}}^{\mathrm{cal}}\right)$ for the $o-, m$-, and $p$-xylenes, ethylbenzene and toluene, and sorption coefficient $\left(\log K_{\mathrm{p}}^{\mathrm{cal}}\right)$ for di, tri- and tetra-chlorobenzene were predicted using the QSARs developed in the present study.

The $\log K_{\mathrm{oc}}^{\exp }$ obtained from Dewulf et al. (1996) as well as the $\log K_{\mathrm{oc}}^{\mathrm{cal}}$ for different models are given in Table 4. A comparison between the model predicted $\log K_{\mathrm{oc}}^{\mathrm{cal}}$ values (using the models developed in this study) and corresponding experimental $\log K_{\mathrm{oc}}^{\exp }$ values for the pollutants obtained by Dewulf et al. (1996) along with the statistical tests estimating the "goodness of fit" reveal that the Kow model and MCI polynomial models (of zeroth and first order) were clearly superior $\left(r^{2}>0.97\right)$ when compared with the other QSARs. It was also found that LSE as well as MCI linear first order models also yielded fairly good correlation coefficients $\left(r^{2}=0.83\right.$ and 0.88 , respectively).

A comparison between the model predicted $\log$ $K_{\mathrm{p}}^{\text {cal }}$ values (using the models developed in this study) and corresponding experimental $\log K_{\mathrm{p}}^{\exp }$ values for the pollutants obtained by Mader et al. (1997) along with the statistical tests estimating the "goodness of fit", as seen from Table 5, reveal that, here too, the Kow, LSE, MCI1IS, and MCI1PIS models were found to give rather superior goodness of fit based on the chi square test as well as SEE and $r^{2}$ analyses. This underscores the robustness and versatility of the QSARs developed and calibrated in the present study. Clearly, the QSARs were able to estimate sorption coefficients for, both, the natural soil/ sediment type sorbent (mineral surface impregnated with natural organic carbon) as well as bare mineral surface. Normally polynomial models would yield higher $r^{2}$ but may not be favoured in large computational schemes. Linear models however, may be favoured better due to their simplicity and the shorter time required for computation. In this light, it is encouraging to note that Kow, LSE and MCI linear models have fairly high $r^{2}$ values and may prove to be more widely acceptable.

As stated earlier, sorption at the sediment-water interface comprises of sorption onto mineral surfaces and partitioning into natural organic carbon. The work presented here as well as the results of Dewulf et al. (1996) are typically resultant of contribution from mineral surface as well as natural organic carbon. Mader et al. (1997), however, have conducted experiments on bare mineral surfaces, namely $\alpha-\mathrm{Al}_{2} \mathrm{O}_{3}$ and $\alpha-\mathrm{Fe}_{2} \mathrm{O}_{3}$. Their work throws light on the role of mineral surface and ionic strength in sorption equilibria for chlorinated benzene-water system. Comparing the toluene $\log K_{\mathrm{oc}}^{\exp }$ results of the present work with the $\log K_{\mathrm{oc}}^{\exp }$ data of Dewulf et al. (1996), it can be seen that sorption is higher for Dewulf et al. (1996) as compared to the present work. This could be attributed to the extent of organic carbon and the

Table 4. Model predicted $\log K_{\mathrm{oc}}^{\mathrm{calc}}$ values (using the models developed in this study) and corresponding experimental log $K_{\mathrm{oc}}^{\mathrm{calc}}$ values for the pollutants obtained by Dewulf et al. (1996) along with the statistical tests estimating the goodness of fit

\begin{tabular}{|c|c|c|c|c|c|c|c|c|}
\hline \multirow[t]{2}{*}{ Pollutant } & \multirow[t]{2}{*}{ Sorbent } & \multirow[t]{2}{*}{$\log K_{\mathrm{oc}}^{\exp }(\mathrm{L} / \mathrm{g})$} & \multicolumn{6}{|c|}{ Calculated $\log K_{\mathrm{oc}}^{\mathrm{calc}}$ values using a given QSAR model } \\
\hline & & & $\begin{array}{l}\text { Kow } \\
\text { model } \\
\text { with IS }\end{array}$ & $\begin{array}{l}\text { LSE } \\
\text { model } \\
\text { with IS }\end{array}$ & $\begin{array}{l}\text { MCI0PIS } \\
\text { model } \\
\text { with IS }\end{array}$ & $\begin{array}{l}\text { MCI1IS } \\
\text { model } \\
\text { with IS }\end{array}$ & $\begin{array}{l}\text { MCI1PIS } \\
\text { model } \\
\text { with IS }\end{array}$ & $\begin{array}{l}\text { MCI2PIS } \\
\text { model } \\
\text { with IS }\end{array}$ \\
\hline Toluene & Belgian & 4.7131 & 2.203 & 2.499 & 2.119 & 2.102 & 2.148 & 2.139 \\
\hline Ethylbenzene & Continental & 5.156 & 2.452 & 2.744 & 2.247 & 2.368 & 2.320 & 2.209 \\
\hline$o$-Xylene & Shelf, & 5.134 & 2.436 & 2.658 & 2.239 & 2.300 & 2.302 & 2.278 \\
\hline$m$-Xylene & North Sea & 5.175 & 2.479 & 2.658 & 2.239 & 2.297 & 2.301 & 2.293 \\
\hline$p$-Xylene & Sediment & 5.181 & 2.468 & 2.742 & 2.239 & 2.297 & 2.301 & 2.293 \\
\hline \multicolumn{3}{|l|}{ Chisquare test $(\alpha)$} & 0.005 & 0.027 & 0.001 & 0.002 & 0.002 & 0.001 \\
\hline \multirow{2}{*}{\multicolumn{3}{|c|}{ SEE }} & 1.490 & 1.350 & 1.598 & 1.566 & 1.565 & 1.583 \\
\hline & & & 0.996 & 0.837 & 0.986 & 0.889 & 0.974 & 0.758 \\
\hline \multicolumn{3}{|l|}{$r^{2}$} & & & & & & \\
\hline
\end{tabular}


Table 5. Model predicted $\log K_{\mathrm{p}}^{\text {calc }}$ values (using the models developed in this study) and corresponding experimental log $K_{\mathrm{p}}^{\text {exp }}$ values for the pollutants obtained by Mader et al. (1997) along with the statistical tests estimating the goodness of fit

\begin{tabular}{|c|c|c|c|c|c|c|c|c|}
\hline \multirow[t]{2}{*}{ Pollutant } & \multirow[t]{2}{*}{ Sorbent } & \multirow[t]{2}{*}{$\log K_{\mathrm{p}}^{\exp }(\mathrm{L} / \mathrm{g})$} & \multicolumn{6}{|c|}{ Calculated $\log K_{\mathrm{p}}^{\text {calc }}$ values using a given QSAR model } \\
\hline & & & $\begin{array}{l}\text { Kow } \\
\text { model } \\
\text { with IS }\end{array}$ & $\begin{array}{l}\text { LSE } \\
\text { model } \\
\text { with IS }\end{array}$ & $\begin{array}{l}\text { MCI0PIS } \\
\text { model } \\
\text { with IS }\end{array}$ & $\begin{array}{l}\text { MCI1IS } \\
\text { model } \\
\text { with IS }\end{array}$ & $\begin{array}{l}\text { MCI1PIS } \\
\text { model } \\
\text { with IS }\end{array}$ & $\begin{array}{l}\text { MCI2PIS } \\
\text { model } \\
\text { with IS }\end{array}$ \\
\hline 1,4-Dichlorobenzene & $\mathrm{Al}_{2} \mathrm{O}_{3}$ & 0.6542 & 1.840 & 1.847 & 1.581 & 1.653 & 1.586 & 1.588 \\
\hline 1,2,4-trichlorobenzene & $\mathrm{Al}_{2} \mathrm{O}_{3}$ & 1.0414 & 2.159 & 2.039 & 1.614 & 1.897 & 1.483 & 1.566 \\
\hline $1,2,3,4$ tetrachlorobenzene & $\mathrm{Al}_{2} \mathrm{O}_{3}$ & 1.6749 & 2.522 & 2.348 & 1.522 & 2.143 & 1.144 & 1.446 \\
\hline 1,4-Dichlorobenzene & $\mathrm{Fe}_{2} \mathrm{O}_{3}$ & 1.0212 & 1.840 & 1.847 & 1.581 & 1.654 & 1.586 & 1.588 \\
\hline $1,2,4$ trichlorobenzene & $\mathrm{Fe}_{2} \mathrm{O}_{3}$ & 1.3654 & 2.159 & 2.039 & 1.614 & 1.897 & 1.483 & 1.566 \\
\hline $1,2,3,4$ tetrachlorobenzene & $\mathrm{Fe}_{2} \mathrm{O}_{3}$ & 1.7218 & 2.522 & 2.348 & 1.522 & 2.143 & 1.144 & 1.446 \\
\hline Chi square test $(\alpha)$ & & & 0.771 & 0.820 & 0.961 & 0.905 & 0.921 & 0.959 \\
\hline \multirow[t]{2}{*}{ SEE } & & & 0.576 & 0.524 & 0.319 & 0.419 & 0.355 & 0.320 \\
\hline & & & 0.858 & 0.859 & 0.418 & 0.855 & 0.823 & 0.788 \\
\hline$r^{2}$ & & & & & & & & \\
\hline
\end{tabular}

ionic strength, which is more for Dewulf et al. (1996) as compared to the present work.

\section{CONCLUSIONS}

Sorption experiments were carried out on Patalganga River sediment using the bottle point method for four chlorinated benzenes and two chlorinated phenols (one pollutant at a time) at different background ionic strengths $(0.01,0.05$ and $0.1 \mathrm{M})$ at $\mathrm{pH}$ of $6.5 \pm 0.1$. The sorption capacity $\left(K_{\mathrm{p}}^{\exp }\right)$, obtained by plotting the linear isotherm, increased with increase in hydrophobicity of the pollutant molecule. Also, amongst the pollutants employed, the sorption capacity $\left(K_{\mathrm{p}}^{\exp }\right)$ increased with increase in the background IS of the system. Among the various models developed in the present study, the Kow model incorporating IS $\left(r^{2}=0.60, \operatorname{SEE}=0.35\right)$ and the LSE model without and with IS $\left(r^{2}=0.60\right.$ and 0.67 , $\mathrm{SEE}=0.35$ and 0.33 , respectively), were found to be relatively superior.

Validation of the developed QSARs by comparing the sorption parameters experimentally measured $\left(\log K_{\mathrm{oc}}^{\exp }\right)$ by Dewulf et al. (1996) and Mader et al. (1997) with the model predicted $\log K_{\mathrm{oc}}^{\mathrm{cal}}$ values (using the QSARs developed in this study) revealed that the linear models (Kow, LSE, and MCI1IS models) were found to give rather superior "goodness of fit" based on SEE, $r^{2}$, and chi square tests.

\section{REFERENCES}

Abdul A. S., Gibson T. L. and Rai D. N. (1990) Use of humic acid solution to remove organic contaminants from hydrogeologic systems. Environ. Sci. Technol. 24, 328-333.

Al-Bahrani K. S. and Martin R. J. (1976) Water Res. 10, 731-736.

Allison L. E. (1965) In Methods of soil analysis, Part 1, eds C. A. Black, D. D. Evans, J. L. White, L. E. Ensminger and F. E. Clark, pp. 371-373. American Society of Agronomy, Madison, WI.

Baker J. R., Mihelcic J. R., Luehrs D. C. and Hickey J. P. (1997) Evaluation of estimation methods for organic carbon normalized sorption coefficients. Water Environ. Res. 69, 136-145.

Banerji S. K., Wei S. M. and Bajpai R. K. (1993) Pentachlorophenol Interaction with soil. Water Air Soil Pollut. 69, 149-163.

Belfort G. (1979) Selective adsorption of organic homologues onto activated carbon from dilute aqueous solutions. Solvophobic interaction approach and correlation of molar adsorptivity with physicochemical parameters. Environ. Sci. Technol. 13, 939-946.

Belfort G., Altshuler G. L., Thallam K. K., Feerick Jr. C. P. and Woodfield K. L. (1984) Selective adsorption of organic homologues onto activated carbon from dilute aqueous solutions: Solvophobic interaction approach IV. Effect of simple structural modifications with aliphatics. A.I.Ch.E.J. 30, 197-207.

Blum D. J. W. and Speece R. E. (1990) Determining chemical toxicity to aquatic species. Environ. Sci. Technol. 24, 284-293.

Blum D. J. W., Suffet I. H. and Duguet J. P. (1994) Quantitative structure activity relationship using molecular connectivity for the activated carbon adsorption of organic chemicals in water. Water Res. 28, 687-699.

Breedveld G. D., Olstad G. and Aagaard P. (1997) Treatment of jet fuel-contaminated runoff water by subsurface infiltration. Bioremed. J. 1, 77-88.

Brennan R. A., Nirmalakhandan N. N. and Speece R. E. (1998) Comparison of predictive methods for Henry's law coefficients of organic chemicals. Water Res. 32, 1901-1911.

Chiou C. T. (1983) Partition equilibrium of nonionic organic compound between soil organic matter and water. Environ. Sci. Technol. 17, 227-231.

Dewulf J., Dewettinck T., De Visscher A. and Van Langenhove H. (1996) Sorption of chlorinated $C_{1^{-}}$and $\mathrm{C}_{2}$-hydrocarbons and monocyclic aromatic hydrocarbons on sea sediments. Water Res. 30, 3130-3138.

Dobbs R. A., Wang L. and Govind R. (1989) Sorption of toxic organic compounds on waste water solids: Correlation with fundamental properties. Environ. Sci. Technol. 23, 1092-1097.

Dowdy D. L., Mckone T. E. and Hseh D. P. H. (1996) Prediction of chemical biotransfer of organic chemicals from cattle diet into beef and milk using the molecular connectivity index. Environ. Sci. Technol. 30, 984-989.

Dunnivent F. M., Elzerman A. W., Jurs P. C. and Hasan M. N. (1992) Quantitative structure-property relationship for aqueous solubilities and Henry's law constants of polychlorinated biphenyls. Environ. Sci. Technol. 26, 1567-1573. 
Engebretson R. R. and Wandruszka R. V. (1998) Kinetic aspects of cation-enchanced aggregation in aqueous humic acids. Environ. Sci. Technol. 32, 488-493.

Gao J. P., Maguhn J., Spitzauer P. and Kettrup A. (1998) Sorption of pesticides in the sediment of the Teufelsweiher pond (Southern Germany) II Competitive adsorption, desorption of aged residues and effect of dissolved organic carbon. Water Res. 32, 2089-2094.

Garbarini D. R. and Lion L. W. (1986) Influence of the nature of soil organics on the sorption of toluene and trichloroethylene. Environ. Sci. Technol. 20, 1263-1269.

Haderlein S. B., Weissmahr K. W. and Schwarzenbach R. P. (1996) Specific Adsorption of nitroaromatic explosives and pesticides to clay minerals. Environ. Sci. Technol. 30, 612-622.

Hesse P. R. (1971) A Text Book of Soil Chemical Analysis, pp. 88-105. John Murray (Publishers) Ltd., London.

Hickey J. P. and Passino-Reader D. R. (1991) Linear solvation energy relationships: 'Rules of Thumb' for estimation of variable values. Environ. Sci. Technol. 25, $1733-1760$

Kamlet M. J., Doherty R. M., Abboud J. M., Abrahman M. H. and Taft R. W. (1986) Solubility: A new look. Chemtech 9, 566-576.

Karickhoff S. W. (1981) Semi-empirical estimation of sorption of hydrophobic pollutants on natural sediments and soils. Chemosphere 8, 833-846.

Karickhoff S. W. (1984) Organic pollutant sorption in aquatic systems. J. Hydraulic Eng. 110, 707-735.

Karickhoff S. W., Brown D. S. and Scott T. A. (1979) Sorption of hydrophobic pollutants on natural sediments. Water Res. 13, 241-248.

Keiding K. and Nielsen P. H. (1997) Desorption of organic macromolecules from activated sludge: Effect of ionic composition. Water Res. 31, 1665-1672.

Kier L. B. and Hall L. H. (1976) Molecular Connectivity in Chemistry and Drug Research. Academic Press, New York.

Lane W. F. and Loehr R. C. (1995) Predicting aqueous concentrations of polynuclear aromatic hydrocarbons in complex mixtures. Water Environ. Res. 13, 169-173.

Lee J., Crum J. R. and Boyd S. A. (1989) Enhanced retention of organic contaminants by soils exchanged with organic cations. Environ. Sci. Technol. 23, $1365-1372$

Luehrs D. C., Hickey J. P., Nilsen P. E., Godbole K. A. and Rogers T. N. (1996) Linear solvation energy relationship of the limiting partition coefficient of organic solutes between water and activated carbon. Environ. Sci. Technol. 30, 143-152.

Luthy R. G., Aiken G. R. and Westall J. C. (1997) Sequestration of hydrophobic organic contaminants by geosorbents. Environ. Sci. Technol. 31, 3341-3349.

Mader B. T., Uwe-Goss K. and Eisenreich S. J. (1997) Sorption of nonionic, hydrophobic organic chemicals to mineral surfaces. Environ. Sci. Technol. 31, 1079-1086.

McGinley P. M., Katz L. E. and Weber W. J. (1993) A distributed reactivity model for sorption by soils and sediments. 2. Multicomponent systems and competitive effects. Environ. Sci. Technol. 27, 1524-1531.

Means J. C., Woods S. G., Hassett J. J. and Banwart W. L. (1980) Sorption of P.A.H by sediments and soils. Environ. Sci. Technol. 14, 1524-1528.

Meylan W., Howard P. H. and Boethling R. S. (1992) Molecular topology/fragment contribution method for predicting soil sorption coefficients. Environ. Sci. Technol. 26, 1560-1567.

Murphy E. M., Zachara J. M., Smith S. C., Phillips J. L. and Wletsma T. W. (1994) Interaction of hydrophobic organic compounds with mineral-bound humic substances. Environ. Sci. Technol. 28, 1291-1299.

Nielsen P. H., Bjerg P. L., Nielsen P., Smith P. and Christensen T. H. (1996) In situ and laboratory determined first-order degradation rate constants of specific organic compounds in an aerobic aquifer. Environ. Sci. Technol. 30, 31-37.

Nirmalakhandan N. N., Brennan R. A. and Speece R. E. (1997) Predicting henry's law constant and the effect of temperature on henry's law constant. Water Res. 31, $1471-1481$.

Nirmalakhandan N. N. and Speece R. E. (1988) QSAR model for predicting henry's constant. Environ. Sci. Technol. 22, 1349-1357.

Nirmalakhandan N. N. and Speece R. E. (1989) Prediction of aqeuous solubility of organic chemicals bases on molecular structure 2. Application to PNAs, PCBs, PCDDs, etc. Environ. Sci. Technol. 23, 708-713.

Nirmalakhandan N. N. and Speece R. E. (1993) Prediction of activated carbon adsorption capacities for organic vapors using quantitative structure-activity relationship methods. Environ. Sci. Technol. 27, 1512-1516.

Piwoni P. S. and Banerjee S. (1989) Sorption of volatile organic solvents from aqueous solution onto subsurface solids. J. Contam. Hydrol. 4, 163-179.

Prakash J., Nirmalakhandan N. N. and Speece R. E. (1994) Prediction of activated carbon adsorption isotherms for organic vapors. Environ. Sci. Technol. 28, 1403-1409.

Romkens P. F. A. M. and Dolfing J. (1998) Effect of Ca on the solubility and molecular size distribution of DOC and $\mathrm{Cu}$ binding of soil solution samples. Environ. Sci. Technol. 32, 363-369.

Sablijic A., Gusten H., Hermens J. and Opperhulzen A. (1993) Modeling octanol/water partition coefficients by molecular topology: Chlorinated benzenes and biphenyls. Environ. Sci. Technol. 27, 1394-1402.

Schwarzenbach R. P., Gschwend P. H. and Imboden D. M. (1993) Envrionmental Organic Chemistry. Wiley, New York, 681.

Shahalam A. B., Biouss A., Ayoub G. M. and Acra A. (1997) Competitive adsorption phenomena of petrochemicals - benzene, toluene, and xylene in hexane in fixedbeds of sands. Water Air and Soil Pollut. 95, 221-235.

Urano K., Omori S. and Yamamoto E. (1982) Prediction method for adsorption capacities of commercial activated carbons in removal of organic vapors. Environ. Sci. Technol. 16, 10-14.

Valsaraj K. T. (1989) Partitioning of hydrophobic nonpolar volatile organics between the aqueous and surfactant aggregate phases on alumina. Sep. Sci. Technol. 24, 1191-1205.

Valsaraj K. T. and Thibodeaux L. J. (1989) Relationships between micelle-water and octanol-water partition constants for hydrophobic organics of environmental interest. Water Res. 23, 183-189.

Weber W. J., McGinley P. M. and Katz L. E. (1991) Sorption phenomena in subsurface systems: Concepts, models and effect on contaminant fate and transport. Water Res. 25, 499-528.

Westall J. C., Leuenberger C. and Schwarzenbach R. P. (1985) Influence of $\mathrm{pH}$ and ionic strength on the aqueousnonaqueous distribution of chlorinated phenols. Environ. Sci. Technol. 19, 193-198.

Xia G. and Ball W. P. (1999) Adsorption-partitioning uptake of nine low-polarity organic chemicals on a natural sorbent. Environ. Sci. Technol. 33, $262-269$.

$\mathrm{Xu} \mathrm{S}$. and Nirmalakhandan N. N. (1998) Use of QSAR models in predicting joint effects in multi-component mixture of organic chemicals. Water Res. 32, 2391-2399. 